\title{
Effect and Compact on Life Quality of the patients of Minimally Invasive Total Hip Replacement and Traditional Total Hip Arthroplasty
}

\author{
Yi Zou, Yi Xu* \\ Department of Orthopaedics, The Second Hospital of Jingzhou, Jingzhou, Hubei Province,434020, China. \\ *Corresponding author: Yi Xu, E-mail: 6939904@qq.com
}

Keywords: minimally invasive hip replacement; traditional hip replacement; hip arthropathy; efficacy; life quality

\begin{abstract}
To investigate the application of minimally invasive total hip replacement and traditional hip replacement in the treatment of advanced hip arthropathy, and to evaluate their therapeutic effect and life quality compact, a total of 76 patients with advanced hip disease who were treated between April 2015 and July 2017 were enrolled in this study. According to the randomized digital table method, 38 patients in the reference group were treated with traditional hip replacement. The 38 patients in the analysis group were treated with minimally invasive hip replacement surgery and the clinical therapeutic effect was summarized. Results are as follows: (1) Efficacy: The operation time of the analysis group was longer than that of the control group, but the amount of bleeding during operation and postoperative drainage were significantly less than those of the control group $(\mathrm{P}<0.05)$. After the treatment, VAS score and Harris score are improved in both groups. And in pairwise comparison, the improvement in the analysis group is higher $(\mathrm{P}<0.05)$. (2)And quality of life: After treatment, the quality of life scores of the two groups were significantly improved in physical function, social function, body pain, emotional performance, mental health and activity ability, and the analysis group was significantly higher than that of the control group $(p<0.05)$. In consequence, compared with the traditional hip replacement, minimally invasive total hip replacement is more effective in the treatment of advanced hip arthroplasty. It is helpful to reduce the intraoperative blood loss, postoperative drainage and pain score, early recovery of the affected joint function, and improve the life quality of the patients, thus having important practical and promotional value.
\end{abstract}

As the clinical research into minimally invasive technique continues to deepen, small incision THA, with its small damage and many other advantages, gradually becomes widely used in clinical. In this study, 76 patients with advanced hip disease who were treated between April 2015 and July 2017 were enrolled in a comparative study to investigate the application of minimally invasive and traditional hip replacement on the treatment of advanced hip disease, evaluate the treatment effect and compact to the life quality of the patients. The purpose of this study is providing guidance for hip disease treatment programs. And the report is as follows:

\section{DATA AND METHODS}

\subsection{General data}

In this study,76 cases of patients with advanced hip disease admitted from April 2015 to July 2017 were enrolled in a comparative study; Inclusion criteria: the patients admitted to hospital were confirmed by X-ray examination, and the group of patients had no history of hip replacement, and no abnormalities in the hip structure examination; Exclusion criteria: (1) hip dysplasia; (2) severe traumatic hip; (3) unaware of the contents of this study; (4) psychiatric diseases;

The 76 patients were randomly divided into two groups. Namely, 38 cases in the control group, including 22 males and 16 females, aged 38-70 years (mean age $53.9 \pm 9.3$ years). In the group, there were 3 cases of femoral neck fracture, 4 cases of rheumatoid arthritis inflammation, 18 cases of femoral head necrosis, and 13 cases of osteoarthritis; And 38 cases in the analysis group included 20 males and 18 females, aged 36 to 69 years, mean age $(54.2 \pm 9.5)$ years, of which 4 cases were 
femoral neck fracture, 4 cases were rheumatoid arthritis, 19 cases were osteonecrosis of the femoral head, and 11 cases were osteoarthritis; The general data between the two groups had no significant difference ( $p>0.05)$, hence comparable.

\subsection{Method}

\subsubsection{Traditional THA treatment}

The control group received conventional THA. That is, preoperative general anesthesia, and the patient take lateral position on the healthy side. Incision was made at the upper spine between the greater trochanter behind the iliac bone, fully exposing the femoral greater trochanter and its subsidiary tissues, and then the sciatic nerve was separated, and the tendons of outward rotator and quadratus femoris were cut revealing the hip capsule. Make incision and removal, and then install the prepared prosthesis, adjust hip mobility, length, stability until satisfaction and do the appropriate wound cleaning, drainage tube placement, suture incision and other measures, followed by follow-up rehabilitation training in lower limbs.

\subsubsection{Minimally invasive THA treatment}

The analysis group underwent minimally invasive THA, namely: preoperative general anesthesia, patients take lateral position on the healthy side, make the incision at the femoral shaft in front of the greater trochanter with an appropriate length of $6 \sim 10 \mathrm{~cm}$, and then gradually cut the fascia lata along the fiber for the gluteal muscle greater trochanter exposure, peel the gluteal muscle and gluteal muscle to expose the joint capsule, remove the femoral head and then install the prepared prosthesis, followed measures consistent with that of the control group.

\subsection{Efficacy criteria}

(1) Efficacy: The data of operation time, intraoperative blood loss, postoperative drainage and other data were statistically analyzed; the visual analog scale (VAS) was used to evaluate the pain performance of the two groups. With a total score of 10 points, the high score means that the pain is more serious. The Harris scoring system is used to evaluate the patient's functional recovery. There are three dimensions in the table, the pain, function and range of activities which totals 100 points. The higher the score, the better the functional recovery. (2)The life quality: The Concise Health Questionnaire (SF-36) developed by the Boston Institute of Health in the United States was used to assess the patient's life quality. The table includes six dimensions: physical function, social function, body pain, emotional performance, mental health, and activity ability. With a total score of 100 points, the higher the score, the better the quality of life.

\subsection{Statistical methods}

SPSS 21.0 statistical software was used to complete the data processing operations. The difference between the samples was statistically significant with $\mathrm{P}<0.05$; the normal distribution of measurement data "mean \pm standard deviation" using an independent sample test; count data "percentage" was checked by Chi-square.

\section{RESULTS}

\subsection{The difference between the two groups of treatment indicators}

The operation time of the analysis group was longer than that of the control group, but the intraoperative blood loss and postoperative drainage were significantly less than those of the control group (Table 1). 
Table 1 Difference between the two groups of treatment indicators $(\bar{x} \pm s)$

\begin{tabular}{ccccc}
\hline Group & Cases & $\begin{array}{c}\text { Operation } \\
\text { time }(\mathrm{min})\end{array}$ & $\begin{array}{c}\text { Intraoperative } \\
\text { blood loss }\end{array}$ & $\begin{array}{c}\text { Postoperative } \\
\text { drainage }\end{array}$ \\
\hline $\begin{array}{c}\text { Analysis } \\
\text { group }\end{array}$ & 38 & $92.6 \pm 16.9$ & $276.5 \pm 50.3$ & $301.4 \pm 52.9$ \\
$\begin{array}{c}\text { Control } \\
\text { group }\end{array}$ & 38 & $77.9 \pm 18.3$ & $487.3 \pm 50.9$ & $511.3 \pm 51.6$ \\
$t$ & $/$ & 3.64 & 18.16 & 17.51 \\
P & $/$ & $<0.05$ & $<0.05$ & $<0.05$ \\
\hline
\end{tabular}

\subsection{Differences between the VAS score and Harris score of the two groups of patients}

After treatment, the VAS score and Harris score improved in both groups. In any pairwise comparisons, the analysis group improved more significantly $(\mathrm{P}<0.05)$ (Table 2$)$;

Table 2 Differences between the VAS score and Harris score of the two groups of patients $(\bar{X} \pm s)$

\begin{tabular}{ccccccccc}
\hline \multirow{2}{*}{ Group } & Case & \multicolumn{2}{c}{ VAS score } & \multicolumn{2}{c}{ Harris score } & $t_{\text {Intra }}$ & $t_{\text {Intra }}$ & $\mathrm{P}$ \\
\cline { 3 - 6 } & & $\begin{array}{c}\text { Before } \\
\text { treatment }\end{array}$ & $\begin{array}{c}\text { After } \\
\text { treatment }\end{array}$ & $\begin{array}{c}\text { Before } \\
\text { treatment }\end{array}$ & $\begin{array}{c}\text { After } \\
\text { treatment }\end{array}$ & $\begin{array}{c}\text { gas } \\
\text { group }\end{array}$ & Harris & \\
\hline $\begin{array}{c}\text { Analysi } \\
\text { s group }\end{array}$ & 38 & $7.45 \pm 1.50$ & $1.91 \pm 0.75$ & $38.11 \pm 7.16$ & $92.13 \pm 6.01$ & 20.36 & 35.62 & $<0.05$ \\
$\begin{array}{c}\text { Control } \\
\text { group }\end{array}$ & 38 & $7.51 \pm 1.42$ & $2.68 \pm 0.70$ & $37.40 \pm 7.32$ & $84.35 \pm 7.02$ & 18.81 & 28.54 & $<0.05$ \\
$t$ & $/$ & 0.18 & 4.63 & 0.43 & 5.19 & $/$ & $/$ & $/$ \\
P & $/$ & $>0.05$ & $<0.05$ & $>0.05$ & $<0.05$ & $/$ & $/$ & $/$ \\
\hline
\end{tabular}

2.3 Differences in life quality score pf the two groups

After treatment, the scores of physical quality, social function, body pain, emotional performance, mental health, activity ability and other life quality scores in both groups were significantly improved, and all dimensions of the analysis group were significantly higher than that of the control group (p $<0.05$ ) (table 3).

Table 3 Difference between the life quality scores of the two groups ( $\bar{x} \pm s$, points)

\begin{tabular}{|c|c|c|c|c|c|c|c|}
\hline Group & Time & $\begin{array}{l}\text { Physical } \\
\text { function }\end{array}$ & $\begin{array}{l}\text { Social } \\
\text { function }\end{array}$ & $\begin{array}{l}\text { Body } \\
\text { pain }\end{array}$ & $\begin{array}{l}\text { Emotional } \\
\text { performance }\end{array}$ & $\begin{array}{l}\text { Mental } \\
\text { health }\end{array}$ & $\begin{array}{l}\text { Activity } \\
\text { ability }\end{array}$ \\
\hline \multirow[t]{2}{*}{$\begin{array}{l}\text { Analysis group } \\
\text { (38) }\end{array}$} & $\begin{array}{l}\text { Before } \\
\text { treatment }\end{array}$ & $46.2 \pm 10.2$ & $50.3 \pm 10.5$ & $\begin{array}{c}46.1 \pm 1 \\
0.1\end{array}$ & $63.5 \pm 11.9$ & $63.2 \pm 13.1$ & $55.3 \pm 10.1$ \\
\hline & $\begin{array}{c}\text { After } \\
\text { treatment }\end{array}$ & $89.3 \pm 10.4$ & $90.0 \pm 13.2$ & $\begin{array}{c}90.2 \pm 1 \\
0.3\end{array}$ & $89.1 \pm 11.2$ & $89.4 \pm 12.8$ & $91.1 \pm 10.3$ \\
\hline \multirow[t]{2}{*}{$\begin{array}{c}\text { Control group } \\
\text { (38) }\end{array}$} & $\begin{array}{l}\text { Before } \\
\text { treatment }\end{array}$ & $46.8 \pm 9.9$ & $50.6 \pm 11.4$ & $\begin{array}{c}47.3 \pm 1 \\
1.8\end{array}$ & $63.7 \pm 11.7$ & $64.0 \pm 13.8$ & $55.9 \pm 9.7$ \\
\hline & $\begin{array}{c}\text { After } \\
\text { treatment }\end{array}$ & $78.4 \pm 10.3$ & $81.1 \pm 10.6$ & $\begin{array}{c}77.4 \pm 9 . \\
8\end{array}$ & $80.0 \pm 10.8$ & $79.3 \pm 10.3$ & $83.3 \pm 11.1$ \\
\hline$t_{\text {Within the analysis }}$ & 1 & 18.24 & 14.51 & 18.84 & 9.66 & 8.82 & 15.30 \\
\hline$t_{\text {Within the control }}$ & I & 13.64 & 12.08 & 12.10 & 6.31 & 5.48 & 11.46 \\
\hline 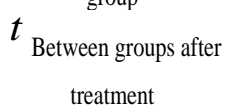 & I & 4.59 & 3.24 & 5.55 & 3.61 & 3.79 & 3.18 \\
\hline $\mathrm{P}$ & 1 & $<0.05$ & $<0.05$ & $<0.05$ & $<0.05$ & $<0.05$ & $<0.05$ \\
\hline
\end{tabular}

\section{DISCUSSION}

Hip bone disease is a common group of clinical symptoms, including osteoarthritis, femoral neck 
fracture, femoral head necrosis and so on. At this stage, clinical treatment of such diseases are mainly total hip replacement (THA). At the same time of reconstructing the hip joint function, THA's biggest purpose is to reduce pain and restore normal limb function. There are multiple THA surgical approach points, such as the front, lateral, anterolateral, posterolateral, etc., of which the most commonly used are the anterolateral approach [1,2]. Traditional THA is more common with the posterolateral approach. Speaking from the physician's point of view, this approach helps to facilitate a wider field of operation and more simple operation, and helps to reduce the gluteal muscle injury. But traditional surgery faces the disadvantage of large irreversible incision, large volume bleeding and other performance, thus to a certain extent, increasing the patient's suffering. Therefore, recent year studies have shown room for improvement [3-5]. From the results of this study, we can see that the operation time of traditional THA surgery group is shorter than that of minimally invasive THA surgery group, but the blood loss and postoperative drainage volume were significantly higher than that of minimally invasive THA surgery group $(\mathrm{P}<0.05)$. Hence proving that minimal invasive surgery does reduce the amount of intraoperative bleeding and postoperative drainage volume [6,7].

In recent years, minimally invasive technique received wide clinical attention. This procedure was derived from the traditional THA. It incorporates the concept of minimally invasive surgery to ensure the advantages of small incision, less injury, less systemic reaction and faster patient recovery. Minimally invasive double-incision THA technology is widely used in clinical treatment since its inception with multiple clinical reports. There have report that[8] pointed out in their study that minimally invasive anterior approach of hip replacement have the advantage of excellent early effect, less trauma, shorter hospital stay, faster recovery and others. In this study, we found that the minimally invasive surgery group had significantly lower intraoperative blood loss and postoperative drainage compared with the conventional THA group. Therefore, it is predicted that the minimally invasive group can promote the early recovery of patients. In addition, the VAS score and Harris score of both groups improved after treatment. In any pairwise comparison, the analysis group improved more $(\mathrm{P}<0.05)$. This suggests that minimally invasive surgery can effectively reduce the pain of patients, while playing an important role in patients' functional recovery. Judging from the life quality of the two groups, the life quality dimensions of the analysis group were significantly higher than that of the control group, and the differences were statistically significant $(p<0.05)$. In the study [9], Writer pointed out that the anterior minimally invasive total hip replacement surgery can achieve satisfactory results, with the advantages of a small incision, less trauma, and can reduce intraoperative bleeding and postoperative complications, while effectively improve the function of the hip hence worth promoting, which is consistent with the results of this study. In terms of complications, this study was not carried out due to a number of factors, but the author predict from the facts of less pain, less intraoperative blood loss and less postoperative drainage, rapid recovery and others that minimally invasive surgery have lower postoperative complications rate, which, however, still need further study to confirm.

In summary, in the treatment of advanced hip disease, compared with the traditional hip replacement, minimally invasive hip replacement have better clinical effect. And is conductive for reducing the amount of bleeding, postoperative drainage and pain score, and have early recovery of joint function, and improve the life quality of the patients, thus having important practical and promotional value.

\section{REFERENCES}

[1] Böhm H, Hagemeyer D, Thummerer Y, Kipping R, Stöckle U, Scheuerer K, "Rehabilitation of gait in patients after total hip arthroplasty: Comparison of the minimal invasive Yale 2-incision technique and the conventional lateral approach”, Gait Posture, vol.04, pp.110-5,2016.

[2] Bel JC, Carret JP,“Total hip arthroplasty with minimal invasive surgery in elderly patients with neck of femur fractures: our institutional experience”, Injury. Vol.01, pp.13-7,2015.

[3] Weber T, Al-Munajjed AA, Verkerke GJ, Dendorfer S, Renkawitz T, "nfluence of minimally invasive total hip replacement on hip reaction forces and their orientations”, $J$ Orthop Res. 
Vol.12, pp.1680-7,2014.

[4] Tumin M, Park KS, Abbas AA, Yoon TR, “Comparison of the Outcome in Bilateral Staged Total Hip Arthroplasty: Modified Two-Incision Minimally Invasive Technique versusthe Conventional Posterolateral”, Chonnam Med J, vol.01, pp.15-20,2014.

[5] Repantis T, Bouras T, Korovessis P, "Comparison of minimally invasive approach versus conventional anterolateral approach for total hip arthroplasty: a randomized controlled trial”, Eur $J$ Orthop Surg Traumatol. Vol.01, pp.111-6,2015.

[6] Musil D, Stehlík J,“Minimally invasive surgical approach for total hip arthroplasty: seven-year results”,Acta Chir Orthop Traumatol Cech,2013.

[7] Reininga IH, Stevens M, Wagenmakers R, Boerboom AL, Groothoff JW, Bulstra SK, Zijlstra W, "Comparison of gait in patients following a computer-navigated minimally invasive anterior approach and a conventional posterolateral approach for total hip arthroplasty: a randomized trial”, $J$ Orthop Res, vol.03, pp.88-94,2013.

[8] Spaans AJ, van den Hout JA, Bolder SB, "High complication rate in the early experience of minimally invasive total hip arthroplasty by the direct anterior approach”,Acta Orthop. vol.04, pp.342-6,2012.

[9] Grano GF, Pavlidou M, Todesco A, Palermo A, Molfetta L, “A new anterolateral surgical approach for total hip replacement”, Joints. vol.03, pp.148-152,2016. 